\title{
The seeds quality of yellow lupine depending on selected agrotechnical factors
}

\section{Jakość siewna nasion łubinu żółtego w zależności od wybranych czynników agrotechnicznych}

\author{
Agnieszka Faligowska ${ }^{1}$, Katarzyna Panasiewicz ${ }^{1}$, Grażyna Szymańska ${ }^{1}$, Monika Bartos-Spychała ${ }^{2}$
}

\section{Summary}

The effect of irrigation and seed dressing on sowing value and vigor of yellow lupine were tested. The irrigation decreased germination energy and capacity, but increased a share of mould and rotting seeds and dead seeds. The vigor tests confirmed a reduction in the quality of seeds. The application of seed dressing (carboxin + thiuram) decreased the number of mould and rotting seeds but significantly increased a share of dead seeds.

Key words: seed dressing, lupine, germination capacity, vigor

\section{Streszczenie}

W badaniach analizowano wpływ deszczowania i zaprawiania na wartość siewną oraz wigor nasion łubinu żółtego. Deszczowanie obniżyło energię i zdolność kiełkowania oraz zwiększyło udział nasion pleśniejących i gnijących, a także nasion zdrowych niekiełkujących. Testy wigorowe potwierdziły obniżenie jakości siewnej. Zastosowanie zaprawy (karboksyna + tiuram) zmniejszyło udział nasion pleśniejących i gnijących, ale istotnie zwiększyło ilość nasion zdrowych niekiełkujących.

Słowa kluczowe: zaprawa nasienna, łubin, zdolność kiełkowania, wigor

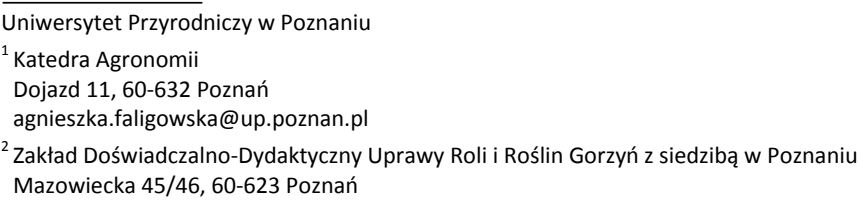




\section{Wstęp / Introduction}

$\mathrm{Na}$ wartość siewną nasion roślin strączkowych może wpływać wiele czynników, zarówno środowiskowych, jak i tych sterowanych przez człowieka. Równomierne zaopatrzenie rośliny $\mathrm{w}$ wodę, w całym sezonie wegetacyjnym może wydatnie polepszyć plony (Koc i Szarek 2011). Dostępność wody dla roślin, uwarunkowana jest przede wszystkim ilością opadów atmosferycznych, bądź stosowaniem nawadniania (Podleśny i Gendarz 2008). Deszczowanie jednak może niekorzystnie wpłynąć na parametry wartości siewnej (Borówczak i Szukała 1992; Szukała 1994; Szukała i Mystek 2006; Faligowska i Szukała 2012).

Podstawowym zabiegiem ochrony roślin stosowanym przez rolników przed siewem jest zaprawianie nasion. Niemniej jednak fungicydy mogą wpływać na wzrost udziału nasion martwych i uszkadzać siewki (MorenoMartinez i wsp. 1998). Jednak według Zhang i Hampton (1999) zaprawa nasienna zastosowana zgodnie $\mathrm{z}$ zaleceniami nie powinna mieć szkodliwego wpływu na rozwój siewek.

Celem doświadczenia było określenie, w jakim stopniu czynniki agrotechniczne, takie jak deszczowanie i zaprawianie mogą modyfikować jakość siewną nasion łubinu żółtego.

\section{Materiały i metody / Materials and methods}

Badania laboratoryjne prowadzono w Katedrze Agronomii Uniwersytetu Przyrodniczego w Poznaniu. Nasiona łubinu żółtego odmiany Mister pochodziły $\mathrm{z}$ doświadczenia polowego założonego w 2011 roku. Czynnikiem I był wariant wodny, a mianowicie materiał zebrany z obiektów niedeszczowanych oraz deszczowanych. Deszczowanie stosowano przy obniżeniu wilgotności gleby do $70 \%$ ppw w warstwie 0-30 cm, w okresach największego zapotrzebowania roślin na wodę. Łączna dawka wody zastosowana od 25.05. do 29.06.2011 roku wyniosła $165 \mathrm{~mm}$. Nasiona zebrano 16 sierpnia 2011 roku, a następnie po trwającym 6 miesięcy okresie spoczynku pożniwnego, materiał został zaprawiony środkiem ochrony roślin zawierającym karboksynę (200 g/l środka) i tiuram (200 g/l środka), który wraz z nasionami niezaprawionymi (kontrola) stanowił czynnik II. Zaprawę zastosowano zgodnie z zaleceniami producenta w dawce $350 \mathrm{ml} / 100 \mathrm{~kg}$ nasion z dodatkiem $700 \mathrm{ml}$ wody.

Badania laboratoryjne przeprowadzono w trzech seriach, w trakcie których wykonano ocenę wartości siewnej oraz testy wigorowe zgodnie z metodyką zalecaną przez Międzynarodowy Związek Oceny Nasion (ISTA 2010). Parametry wartości siewnej stanowiły: energia i zdolność kiełkowania, nasiona anormalnie kiełkujące oraz pleśniejące i gnijące, a także zdrowe niekiełkujące. Testy wigorowe obejmowały: test wzrostu siewki oraz test szybkości wzrostu siewki, które wykonano według metodyki Dąbrowskiej i wsp. (2000). Obliczono również indeks wigoru, który stanowi iloczyn średniej długość kiełka (cm) i średniej zdolności kiełkowania (\%). Wyniki badań poddano ocenie statystycznej, a najmniejszą istotną różnicę oszacowano na poziomie istotności $\alpha=0,05$.

\section{Wyniki i dyskusja / Results and discussion}

Początki wegetacji łubinu żółtego w 2011 roku przebiegały $\mathrm{w}$ mało sprzyjających warunkach meteorologicznych (tab. 1). W okresie kiełkowania i wschodów, a więc w okresie dużego zapotrzebowania na wodę, suma opadów wyniosła zaledwie 4,1 mm. Maj również był suchy, dlatego pod koniec tego miesiąca, kiedy to łubin był w fazie pakkowania zdecydowano się wykonać pierwsze deszczowanie. Największe zapotrzebowanie łubinu na wodę przypada w okresie kwitnienia i zawiązywania strąków, a więc w czerwcu. W miesiącu tym ilość opadów wzrosła, ale nie wystarczyła na pokrycie potrzeb, dlatego zdecydowano się kontynuować deszczowanie. W lipcu natomiast, opady przekroczyły $200 \mathrm{~mm}$, łubin dojrzewał w bardzo trudnych warunkach. Temperatura siegająca blisko $20^{\circ} \mathrm{C}$ oraz wysoka wilgotność mogły sprzyjać zasiedlaniu nasion przez grzyby i pleśnie, które między innymi mogły wpłynąć na obniżenie jakości materiału siewnego. Zdolność kiełkowania nasion $\mathrm{z}$ obiektów niedeszczowanych, na kontroli stanowiła zaledwie $80 \%$, podczas gdy minimalna wartość wymagana dla materiału kwalifikowanego wynosi $85 \%$. Natomiast liczba nasion pleśniejących i gnijących wyniosła aż 19\% (tab. 2).

Tabela 1. Warunki pogodowe w $2011 \mathrm{r}$.

Table 1. Weather conditions in 2011

\begin{tabular}{|c|c|c|c|c|c|c|c|c|}
\hline \multirow{3}{*}{$\begin{array}{l}\text { Miesiąc } \\
\text { Month }\end{array}$} & \multirow{2}{*}{\multicolumn{3}{|c|}{$\begin{array}{c}\text { Temperatura - Temperature } \\
{\left[{ }^{\circ} \mathrm{C}\right]} \\
\text { dekada }- \text { decade } \\
\end{array}$}} & \multirow{3}{*}{$\begin{array}{l}\text { Średnia } \\
\text { Mean }\end{array}$} & \multirow{2}{*}{\multicolumn{3}{|c|}{$\begin{array}{c}\text { Opady - Rainfall } \\
{[\mathrm{mm}]} \\
\text { dekada - decade }\end{array}$}} & \multirow{3}{*}{$\begin{array}{l}\text { Suma } \\
\text { Total }\end{array}$} \\
\hline & & & & & & & & \\
\hline & $\mathrm{I}$ & II & III & & I & II & III & \\
\hline IV & 11,2 & 10,6 & 16,1 & 12,7 & 3,5 & 0,0 & 0,6 & 4,1 \\
\hline $\mathrm{V}$ & 11,4 & 16,7 & 17,7 & 15,3 & 2,6 & 12,2 & 2,7 & 17,5 \\
\hline VI & 20,3 & 17,4 & 17,5 & 18,4 & 8,0 & 16,2 & 38,2 & 62,4 \\
\hline VII & 17,5 & 19,3 & 16,0 & 17,5 & 33,0 & 57,6 & 124,2 & 214,8 \\
\hline VIII & 19,1 & 18,5 & 19,1 & 18,9 & 10,6 & 12,8 & 14,6 & 38,0 \\
\hline
\end{tabular}


Tabela 2. Wartość siewna łubinu żółtego w zależności od czynników doświadczenia [\%]

Table 2. Sowing value of yellow lupine depending on experimental factors [\%]

\begin{tabular}{|c|c|c|c|}
\hline \multirow{2}{*}{$\begin{array}{l}\text { Czynnik doświadczenia } \\
\text { Factor of experiment }\end{array}$} & \multicolumn{3}{|c|}{ Wyszczególnienie - Specification } \\
\hline & $\begin{array}{c}\text { kontrola } \\
\text { control }\end{array}$ & $\begin{array}{c}\text { zaprawa nasienna } \\
\text { seed dressing product }\end{array}$ & $\begin{array}{c}\text { średnia } \\
\text { mean }\end{array}$ \\
\hline \multicolumn{4}{|c|}{ Energia kiełkowania - Germination energy } \\
\hline Niedeszczowane - Non-irrigated & 78 & 87 & 83 \\
\hline Deszczowane - Irrigated & 69 & 62 & 66 \\
\hline Średnia - Mean & 74 & 75 & \\
\hline \multicolumn{4}{|c|}{$\begin{array}{l}\text { NIR }(0,05) \text { dla wariantu wodnego - LSD }(0.05) \text { for irrigation variant }-7,9 ; \text { NIR }(0,05) \text { dla zaprawy nasiennej - LSD }(0.05) \text { for seed } \\
\text { dressing - r.n.; NIR }(0,05) \text { dla interakcji - LSD }(0.05) \text { for interaction }-7,5\end{array}$} \\
\hline \multicolumn{4}{|c|}{ Zdolność kiełkowania - Germination capacity } \\
\hline Niedeszczowane - Non-irrigated & 80 & 90 & 85 \\
\hline Deszczowane - Irrigated & 70 & 65 & 68 \\
\hline Średnia - Mean & 75 & 78 & \\
\hline \multicolumn{4}{|c|}{$\begin{array}{l}\text { NIR }(0,05) \text { dla wariantu wodnego - LSD }(0.05) \text { for irrigation variant }-2,8 ; \text { NIR }(0,05) \text { dla zaprawy nasiennej - LSD }(0.05) \text { for seed } \\
\text { dressing - r.n.; NIR }(0,05) \text { dla interakcji - LSD }(0.05) \text { for interaction }-5,4\end{array}$} \\
\hline \multicolumn{4}{|c|}{ Nasiona pleśniejące i gnijące - Mould and rotting seeds } \\
\hline Niedeszczowane - Non-irrigated & 19 & 1 & 10 \\
\hline Deszczowane - Irrigated & 27 & 4 & 16 \\
\hline Średnia - Mean & 23 & 3 & \\
\hline
\end{tabular}

\begin{tabular}{l|c|c|c}
\hline \multicolumn{3}{|c}{ Nasiona zdrowe niekiełkujące - Dead seeds } & 6 \\
\hline Niedeszczowane - Non-irrigated & 0 & 27 & 3 \\
\hline Deszczowane - Irrigated & 0 & 17 & 14 \\
\hline Średnia - Mean & 0 & & \\
\hline
\end{tabular}

NIR $(0,05)$ dla wariantu wodnego - LSD $(0.05)$ for irrigation variant - 4,1; NIR $(0,05)$ dla zaprawy nasiennej - LSD $(0.05)$ for seed dressing $-2,8$; NIR $(0,05)$ dla interakcji - LSD $(0.05)$ for interaction $-3,9$

r.n. - różnica nieistotna - not significant difference

Badania innych autorów wykazują, że deszczowanie może również wpływać niekorzystnie na wartość siewną nasion roślin strączkowych. Borówczak i Szukała (1992) stwierdzili, że zastosowanie tego czynnika w następstwie wzrostu plonu grochu, mogło obniżyć zdolność kiełkowania nasion tego gatunku. W dalszych badaniach Szukała (1994) potwierdził, negatywny wpływ deszczowania na wartość siewną nasion. W jego doświadczeniach nawadnianie spowodowało istotne obniżenie zdolności kiełkowania łubinu białego o 4\%, a łubinu żółtego o $6 \%$. U Szukały i Mystek (2006) deszczowanie nie miało wpływu na zdolność kiełkowania grochu, ale przyczyniło się do istotnego obniżenia energii kiełkowania nasion. Ponadto Faligowska i Szukała (2012) wykazali, że nasiona łubinu żółtego z obiektów deszczowanych miały istotnie mniejszy wigor o $30,5 \%$, energię kiełkowania o $7,9 \%$, a zdolność kiełkowania o $5,6 \% \mathrm{w}$ porównaniu $\mathrm{z}$ materiałem zebranym z obiektów niedeszczowanych.

W doświadczeniu własnym deszczowanie istotnie obniżyło energię i zdolność kiełkowania o 17\% i spowodowało wzrost udziału nasion pleśniejących i gnijących o $6 \%$ oraz zdrowych niekiełkujących o $11 \%$ (tab. 2). Testy wigorowe potwierdziły spadek jakości siewnej nasion na skutek zastosowania tego czynnika (tab. 3). Nasiona zebrane z obiektów deszczowanych miały siewki istotnie mniejsze, o 0,8 cm, o mniejszej suchej masie $(15,5 \mathrm{mg})$, a ich indeks wigoru był o około $50 \%$ niższy. Nie odnotowano natomiast istotnego wpływu na wigor nasion zaprawy nasiennej ani wzajemnej interakcji pomiędzy tymi czynnikami. Istotne interakcje stwierdzono w przypadku wartości siewnej (tab. 2). Zastosowanie zaprawy nasiennej poprawiło o 9-10\% energię i zdolność kiełkowania nasion zebranych z obiektów niedeszczowanych, a ponadto istotnie zmniejszyło udział nasion pleśniejących i gnijących, aż o $18 \%$. W przypadku nasion pochodzących $\mathrm{z}$ obiektów deszczowanych zastosowanie zaprawy nie wpłynęło na energię i zdolność kiełkowanie, ale również w sposób istotny zmniejszyło ilość nasion pleśniejących i gnijących (o 23\%). Liczba nasion anormalnie kiełkujących kształtowała się na poziomie $1-3 \%$ i nie była istotnie zróżnicowana czynnikami doświadczenia. Zastosowanie środka ochrony roślin w formie zaprawy zwiększyło udział nasion zdrowych niekiełkujących zarówno niedeszczowanych, jak i deszczowanych. Średnio, zaprawa nasienna zawierająca karboksyna i tiuram nie wpłynęła istotnie na energię i zdolność kiełkowania, ale zmniejszyła udział nasion pleśniejących i gnijących o $20 \%$, a zwiększyła liczbę nasion zdrowych niekiełkujących o 17. 
Tabela 3. Wpływ deszczowania na wigor nasion łubinu żółtego

Table 3. The influence of irrigation on vigor of yellow lupine seed

\begin{tabular}{l|c|r}
\hline \multicolumn{1}{c}{ Wyszczególnienie - Specification } & \multicolumn{2}{c}{ Wariant wodny - Irrigation variant } \\
\cline { 2 - 3 } & niedeszczowane - non-irrigated & deszczowane - irrigated \\
\hline Test wzrostu siewki - Seedling growth test $[\mathrm{cm}]$ & 3,6 & 2,4 \\
\hline NIR $(0,05)$ - LSD $(0.05)$ & & 0,48 \\
\hline Test szybkości wzrostu siewki - Seedling growth rate test $[\mathrm{mg}]$ & 16,5 & 15,5 \\
\hline NIR $(0,05)$ - LSD $(0.05)$ & & 0,96 \\
\hline Indeks wigoru - Vigor index & 306,0 & 163,2 \\
\hline NIR $(0,05)$ - LSD $(0.05)$ & & \multicolumn{2}{|c}{45,68} \\
\hline
\end{tabular}

Wyniki innych doświadczeń wskazują na negatywny wpływ zapraw nasiennych na wartość siewną nasion roślin strączkowych. We wcześniejszych badaniach Faligowskiej i wsp. (2012) zastosowanie zaprawy nasiennej o tym samym składzie obniżyło energię kiełkowania nasion łubinu wąskolistnego o $2 \%$, lecz nie miało istotnego wpływu na zdolność kiełkowania i liczbę nasion martwych, a test wzrostu siewki oraz indeks wigoru wykazały pogorszenie wigoru nasion. Nasiona zaprawione karboksyną i tiuramem miały siewki średnio o około $1 \mathrm{~cm}$ mniejsze $\mathrm{w}$ porównaniu do kontroli, a ich indeks wigoru był niższy o 11,3\%. Bieniaszewski i Fordoński (2001) badali wpływ zapraw nasiennych zawierających metalaxyl + thiabendazol oraz furatiokarb na wartość siewną nasion trzech odmian łubinu żółtego. Analiza wyników wykazała istotne obniżenie zdolności kiełkowania z 72 do 38\% na skutek ich jednoczesnego zastosowania. W doświadczeniach Fordońskiego i wsp. (1994) zastosowany w formie zaprawy tiuram obniżył o 10 do $25 \%$ zdolność kiełkowania grochu, łubinu wąskolistnego i żółtego. Ponadto spowodował obniżenie wigoru nasion $\mathrm{u}$ wszystkich badanych gatunków roślin strączkowych. Z kolei Zhang i Hampton (1999) testem elektroprzewodnictwa badali wpływ zapraw fungicydowych na wigor grochu, soi, fasoli i bobiku. Jednak przy zastosowaniu dawek zgodnych z zaleceniami, wigor nasion nie był istotnie zróżnicowany.

\section{Wnioski / Conclusions}

1. Deszczowanie obniżyło energię i zdolność kiełkowania oraz zwiększyło udział nasion pleśniejących i gnijących, a także nasion zdrowych niekiełkujących.

2. Testy wigorowe potwierdziły obniżenie jakości siewnej materiału na skutek nawadniania.

3. Zastosowanie zaprawy nasiennej poprawiło energię i zdolność kiełkowania nasion pochodzących z obiektów niedeszczowanych, a ponadto znacznie zmniejszyło udział nasion pleśniejących i gnijących oraz zwiększyło liczbę nasion zdrowych niekiełkujących zarówno z obiektów niedeszczowanych, jak i deszczowanych.

\section{Literatura / References}

Bieniaszewki T., Fordoński G. 2001. Wpływ stosowanych pestycydów na wzrost, rozwój oraz zdrowotność różnych genotypów łubinu żółtego. Cz. 1. Wpływ Apronu i Prometu na wzrost, rozwój oraz plonowanie 3 odmian łubinu żółtego. Zesz. Nauk. AR Wrocław, Rolnictwo 426 (81): 23-37.

Borówczak F., Szukała J. 1992. Wpływ deszczowania na jakość materiałów siewnych buraków cukrowych, grochu i bobiku. Zesz. Nauk. ATR Bydgoszcz 180, Rol. 32: 67-72.

Dąbrowska B., Pokojska H., Suchorska-Tropiło K. 2000. Metody laboratoryjnej oceny materiału siewnego. SGGW, Warszawa, 91 ss.

Faligowska A., Bartos-Spychała M., Panasiewicz K. 2012. Wpływ okresu przechowywania na wartość siewną i wigor zaprawionych nasion łubinu waskolistnego. [The sowing value and vigour of winter wheat grain depending on storage period and the seed dressing]. Prog. Plant Prot./Post. Ochr. Roślin 51 (1): 28-32.

Faligowska A., Szukała J. 2012. Wpływ deszczowania i systemów uprawy roli na wigor i wartość siewną nasion łubinu żółtego. Nauka Przyroda Technologia 6, 2, \#26. http://www.npt.up-poznan.net/pub/art 6 26.pdf, dostęp: 11.06.2012.

Fordoński G., Górecki R., Bieniaszewski T., Majchrzak B. 1994. Wpływ tiuramu na kiełkowanie, wigor nasion i zdrowotność siewek roślin strączkowych w warunkach stresu chłodnowodnego. s. 81-88. Mat. Konf. „Uszlachetnianie materiałów nasiennych”. PAN, AR-T, Olsztyn, 9-10 czerwiec 1994, 158 ss.

ISTA 2010. Międzynarodowy Związek Oceny Nasion. International Rules for Seed Testing. Bassersdorf, Switzerland.

Koc G., Szarek S. 2011. Efektywność zastosowania wzrastających dawek hydrożelu w uprawie pieczarki dwuzarodnikowej Agaricus bisporus (Lange) Sing. Imbach. J. Agribus. Rural Dev. 4 (22): 115-122.

Moreno-Martinez E., Rivera A., Vazquez Badillo M. 1998. Effect of fungi and fungicides on the preservation of wheat seed stored with high and low moisture content. J. Stored Prod. Res. 34 (4): 231-236.

Podleśny J., Gendarz M. 2008. Wpływ wody uzdatnionej magnetycznie na wzrost, rozwój i plonowanie dwóch genotypów grochu siewnego. Acta Agrophys. 12 (3): 767-776.

Szukała J. 1994. Wpływ czynników agrotechnicznych na plon, skład chemiczny i wartość siewną nasion trzech gatunków łubinu, ze szczególnym uwzględnieniem łubinu białego. Rocz. AR Poznań, Rozpr. Nauk. 245, 87 ss.

Szukała J., Mystek A. 2006. Plonowanie grochu siewnego w zależności od deszczowania, systemów uprawy roli i poziomu nawożenia azotem. Rocz. AR Poznań 380, Rol. 66: 347-355.

Zhang T., Hampton J.G. 1999. Does fungicide seed treatment affect bulk conductivity test results? Seed Sci. Technol. 27 (3): $1041-1045$. 